\title{
Effects of 25 hydroxy vitamin D levels on the severity and asthma control in school age asthma patients
}

Merve Havan, M.D. ${ }^{a}$, Cem H. Razi, M.D., Assoc. Prof. , Ayse D. Bulus, M.D. ${ }^{c}$, Ali O. Köksal, M.D. ${ }^{a}$ and Nesibe Andıran, M.D., Assoc. Prof.

\begin{abstract}
Background. The objective was to determine vitamin $\mathrm{D}$ levels in patients between the ages 6 and 18 years, followed for asthma, and the relation between vitamin $\mathrm{D}$ levels and asthma control and severity.

Materials and Methods. Patients with asthma and healthy volunteers between the ages 6 and 18 years were enrolled into the study as patient and control groups, respectively. Patient demographic information and clinical findings were recorded; a respiratory function test was performed. Body mass index (BMI), 25(OH) $\mathrm{D}$,calcium, phosphorus, alkaline phosphatase, total $\operatorname{IgE}$ and eosinophil levels were determined for all patients. Asthma severity and control conditions were established based on GINA (Global Initiative for Asthma) criteria.

Results. Seventy two patients with asthma and 66 healthy children were included. Compared to the control group, decreased serum vitamin $D$ levels were detected in patient group. Thirty eight $(52.8 \%)$ patients in asthma patient group had vitamin D defficiency; in this group, asthma control was poor and asthma severity was significantly higher. No significant correlation was found between vitamin D levels and gender, obesity, respiratory functions, skin test, serum eosinophil and total IgE levels.

Conclusion. The frequency of vitamin D deficiency and insufficiency was higher in children with asthma, compared to the controls. Lower levels of vitamin D are associated with poor asthma control and increased asthma severity.
\end{abstract}

a. Pediatrics

b. Pediatric Allergy and Immunoloy

c. Pediatric Endocrinology Keçiören Research and Educational Hospital, Ankara, Turkey.

E-mail address:

Ali O. Köksal, M.D.: koksal6623@gmail.com

Key words: asthma, vitamin $D$, asthma control, asthma severity, children.

http:/ / dx.doi.org/10.5546/ aap.2017.eng.336

To cite: Havan M, Razi CH, Bulus AD, et al. Effects of 25 hydroxy vitamin D levels on the severity and asthma control in school age asthma patients. Arch Argent Pediatr 2017;115(4):336-342.
Funding:

None.

Conflict of interest:

None.

Received: 7-4-2016

Accepted: 1-23-2017

\section{INTRODUCTION}

Asthma is a chronic, inflammatory, respiratory tract disease accompanied by hypersensitivity of airways, recurring wheezing episodes, respiratory distress and coughing. ${ }^{1}$ In the last 20-30 years, with the significant surge in asthma, the rate of clinically diagnosed asthma in children and adolescents has increased from $9 \%$ to $17 \% .^{2}$ The results of ISAAC (International Study of Asthma and Allergies in Childhood) study conducted in 56 countries using the same methods, exhibit an asthma frequency varying between $1.6 \%$ $36.8 \%$. $^{3}$

Vitamin D deficiency is a common health problem affecting approximately one million children and adolescents around the world. ${ }^{4}$ According to the data from National Health and Nutrition Examination Survey (NHANES) only a quarter of the adolescents and adults in United States have sufficient levels of Vitamin D. ${ }^{5}$ In addition to its effects on calcium metabolism and bone development, it is also believed to be a potent immune system regulator having a potential role in various allergic diseases. ${ }^{6}$ The fact that Vitamin D receptors (VDR) are present in all cells (brain, heart, stomach, pancreas, mammilla, gonads, $\mathrm{T}$ and $\mathrm{B}$ lymphocytes, monocytes, lungs, etc.) except bones suggests vitamin $\mathrm{D}$ plays a role in the functions of tissues and that it could be associated with a variety of diseases. ${ }^{7}$

Viral infections are a known primary risk factor in the onset of asthma attack. During a viral infection, vitamin $\mathrm{D}$ is responsible from the production of cathelicidinin, an antimicrobial polypeptide. 
Research exhibits vitamin D supplements reduce upper respiratory tract infection significantly. 8,9 vitamin $\mathrm{D}$ regulates inflammatory response by inhibiting the secretion of mediators such as interleukin 2 (IL-2) and interferon $\gamma($ IFN- $\gamma$ ) from $\mathrm{T}$ helper 1 cells and interleukin 4 (IL-4) from T helper 2 cells. ${ }^{10}$

The effect of vitamin D in inflammatory process also influences the response to steroid treatment, which has an important role in asthma treatment. ${ }^{11}$

The aim of this study was to determine whether patients between the ages 6 and 18 years, followed for asthma, are vitamin $\mathrm{D}$ deficient and to investigate the relation between vvitamin $\mathrm{D}$ levels and asthma control and severity.

\section{MATERIALS AND METHODS}

Design: cross-sectional trial.

The study group consisted of asthma patients with persistent wheezing and coughing admitted to the Department of Pediatric Allergy, of Keciören Training and Research Hospital, between April, and June 2014. Inclusion criteria were; being between 6 and 18 years old, having been diagnosed with current asthma. Exclusion criteria were; chronic disease, other than asthma (cystic fibrosis, bronchopulmonary dysplasia.). The control group had no history of chronic disease, lower respiratory tract disease or wheezing, and the age and sex were consistent with the study group who had been admitted to the pediatric department for routine control.

A detailed survey was administered including demographic information, anthropometric measurements, prior vitamin $\mathrm{D}$ treatment, length and properties of asthma symptoms, current atopy status, drugs administered for asthma treatment, asthma management and severity for the last three months, asthma attacks within the previous year, all additional physician diagnosed diseases; physical examination was performed.

Ages, body weight, and height of all patients were recorded. Body mass index (BMI) was calculated as weight $(\mathrm{kg}) /$ height $\left(\mathrm{m}^{2}\right)$ and BMI percentile range was evaluated using Neyzi standards. ${ }^{12}$ Pulmonary function test (PFT) was performed all patients. PFT was measured with an electronic spirometer (calibrated) at the Pediatric Allergy Polyclinic according to American Thoracic Society (ATS) criteria. ${ }^{13} \mathrm{~A}$ pediatric allergy nurse measured FEV1 and FVC by affixing a pin to subjects' noses. It was ensured that the patients had not used bronchodilators within 6 hours, prior to procedure. Skin tests and atopy status of patients being followed for asthma diagnosis were recorded.

Severity of asthma attacks and control status were registred. Severity of attacks was categorized as intermittent, mild persistent, moderate persistent and serious persistent based on the symptoms and findings specified in GINA criteria. $^{1}$

Based on GINA criteria; asthma control status was categorized into three groups as well-controlled, partly- controlled, uncontrolled according to symptom frequency, activity restriction, waking up in the night, $\beta 2$ agonist use, PFT values (PEF, FEV1) and attack count in the previous year. ${ }^{1}$

Additionally, peripheral venous blood samples from all patients were obtained to determine serum parameters calcium, phosphorus, alkaline phosphatase levels that can affect $25(\mathrm{OH}) \mathrm{D}$, complete blood count (eosinophile percent), total $\operatorname{IgE}$ and vitamin D levels. Two milliliters of the venous blood samples taken from patients were transferred into two tubes with EDTA and one of them was used for hemogram analysis by using photometric method with a Beckman brand LH 780 equipment. Eosinophil count over 400 cells/ $\mathrm{mm}^{3}$ was considered eosinophilia. Two milliliters of blood was directly taken into biochemistry tubes for the determination of serum Ca, P, ALP, and IgE. Blood samples placed in biochemistry tubes were rested in room temperature for 10 minutes. Following complete coagulation samples were centrifuged for 5 minutes at 4,500 $\mathrm{rpm}$. Then they were frozen at $-80{ }^{\circ} \mathrm{C}$ until all serum samples can be analyzed. Prior to analyses, samples were rested overnight at $-20^{\circ} \mathrm{C}$ and then thawed at $+4{ }^{\circ} \mathrm{C}$.

From the samples; Ca, P, and ALP was measured using photometric method with a Beckaman AU 680 brand equipment, and Total IgE was measured using nephelometric method with a Beckman Coulter Immage 800 brand equipment. IgE serum levels above 180 (international unit) $\mathrm{IU} / \mathrm{ml}$ were considered elevated values.

Serum vitamin $\mathrm{D}$ levels were determined with $25(\mathrm{OH}) \mathrm{D}$ levels. $25(\mathrm{OH}) \mathrm{D}$ is the major circulatory form with a 2-3 weeks half-life that shows both the exogenous vitamin $D$ intake and the endogenous production. ${ }^{14}$ Circulatory level of biologically active form $1,25(\mathrm{OH})_{2} \mathrm{D}$ is one thousand th of $25(\mathrm{OH}) \mathrm{D}$ and has a short half-life (4-6 hours) that makes it unsuitable for ideal measurements. Two 
milliliters of venous blood samples obtained for vitamin $\mathrm{D}$ measurements were placed into tubes with EDTA and 25(OH)D levels were determined with DiasoninLiaisan brand equipment using chemiluminescenceimmunometric assay. Serum 25(OH)D levels below $15 \mathrm{ng} / \mathrm{ml}$ were considered vitamin $\mathrm{D}$ deficiency, levels between 15 and $20 \mathrm{ng} / \mathrm{ml}$ vitamin D insufficiency, level above $20 \mathrm{ng} / \mathrm{ml}$ normal and levels over $150 \mathrm{ng} / \mathrm{ml}$ were considered vitamin D intoxication. ${ }^{14}$

\section{Ethical aspects}

Our study was approved by the Keciören Training and Research Hospital Ethical Committee (No: B.10.4.ISM.4.06.68.49). Informed consent forms were obtained from the parents of all participants.

\section{Statistical analysis}

Data analysis was performed with SPSS (Statistical Package for Social Sciences) for Windows 15 package program (SPSS Inc.,

TABLE 1. Demographic information of patient and control groups

\begin{tabular}{lccc}
\hline & $\begin{array}{c}\text { Asthma patient } \\
\text { group } \\
\mathbf{n = 7 2}\end{array}$ & $\begin{array}{c}\text { Control } \\
\text { group } \\
\mathbf{n = 6 6}\end{array}$ & $\boldsymbol{p}$ \\
\hline $\begin{array}{l}\text { Gender n, (\%) } \\
\quad \text { Female }\end{array}$ & $38(52.8)$ & $36(54.5)$ & \\
$\quad$ Male & $34(47.2)$ & $30(45.5)$ & 0.830 \\
Age* & $10.28 \pm 2.70$ & $10.81 \pm 2.69$ & 0.198 \\
BMI $\left(\mathrm{kg} / \mathrm{m}^{2}\right)$ & 18.92 & 19.07 & 0.460 \\
BMI n, $(\%)$ & & & \\
$\quad>95$ percentile & $8(53.3)$ & $7(46.7)$ & \\
$\quad$ 85-95 percentile & $3(25)$ & $9(75)$ & 0.200 \\
$\quad 5-85$ percentile & $58(54.2)$ & $49(45.8)$ & \\
$\quad<5$ percentile & $3(52.2)$ & $1(1.5)$ & \\
Total IgE* & $178 \pm 269.6$ & $41.1 \pm 76.85$ & $\mathbf{0 . 0 0 0}$ \\
Eosinophil & $224.2 \pm 170.9$ & $152.1 \pm 171.3$ & $\mathbf{0 . 0 0 3}$ \\
Ca $^{*}$ & $9.81 \pm 0.38$ & $9.81 \pm 0.38$ & 0.061 \\
$\mathrm{P}^{*}$ & $4.35 \pm 0.544$ & $4.2 \pm 0.62$ & 0.551 \\
ALP $^{*}$ & $204 \pm 84.9$ & $198 \pm 69.8$ & 0.946 \\
FEV1 $^{*}$ & $84.84 \pm 12.25$ & $96.15 \pm 9.82$ & $\mathbf{0 . 0 0 0}$ \\
FEV1/FVC $^{*}$ & $110.22 \pm 5.69$ & $112.77 \pm 5.010$ & $\mathbf{0 . 0 0 1}$ \\
\hline
\end{tabular}

*mean \pm SD.
Chicago, IL, USA). Identifying statistics for variables with normal distribution are given as mean \pm standard deviation, variables with nonnormal distribution as median values ( $\mathrm{min}-$ max), and nominal variables are presented as number of cases and percentages.

When the number of groups was two, the significance of differences among averages between the groups was analyzed with Student test and significance of difference between median values was determined with Mann Whitney Test. When the number of groups were more than two, the significance of differences among averages between the groups were determined with ANOVA variance analysis and significance of difference between median values were analyzed with Kruskal Wallis test. Nominal variables were evaluated with Pearson chi square or Fischer exact test. A result of $p<0.05$ was considered statistically significant.

\section{RESULTS}

Seventy-two patients with asthma and 66 healthy children were enrolled into the study as patient and control groups, respectively. The median ages of the asthmatic and healthy control children were $10.28 \pm 2.70$ years and $10.81 \pm 2.69$ years, respectively $(\mathrm{p}=0.198)$ (Table 1$)$. Gender, age, height, weight and BMI were similar between the patients and control groups (Table 1).

Serum total IgE, Ca, P, ALP, eosinophil, FEV1 and FEV1/FVC levels measured for patients with asthma and control groups are presented in Table 1.

Skin test results were positive for $27(37.5 \%)$ and negative for $45(62.5 \%)$ patients followed for asthma.

Data related to vitamin D levels for asthma patients and control groups are presented in Table 2. A significant difference was found when serum vitamin D levels between asthma patients and control groups compared. Detailed investigation of our study groups' revealed $38(52.8 \%)$ patients in asthma patient group and

TABLE 2. Evaluation of asthma patient and control groups based on Vitamin D levels.

\begin{tabular}{lccc}
\hline & $\begin{array}{c}\text { Asthma patient group } \\
\mathbf{n}=\mathbf{7 2}\end{array}$ & $\begin{array}{c}\text { Control group } \\
\mathbf{n}=\mathbf{6 6}\end{array}$ & $p$ \\
\hline Vitamin D level $(\mathrm{ng} / \mathrm{ml})^{*}$ & $14.44 \pm 6.203$ & $17.85 \pm 6.67$ & $\mathbf{0 . 0 0 4}$ \\
Vitamin D level $\mathbf{n},(\%)$ & & & \\
$\quad$ Normal vitamin D level $(>20 \mathrm{ng} / \mathrm{ml})$ & $14(19.4)$ & $23(34.8)$ & $\mathbf{0 . 0 4 1}$ \\
$\quad$ Vitamin D insufficiency / deficiency $(\leq 20 \mathrm{ng} / \mathrm{ml})$ & $58(80.6)$ & $43(65.2)$ & \\
\hline
\end{tabular}

*mean \pm SD. 
$24(38.4 \%)$ subjects in control group had vitamin $\mathrm{D}$ deficiency. Twenty (27.8\%) patients in asthma patients group and $19(28.8 \%)$ had vitamin D insufficiency.

Comparison of vitamin D levels according to the gender; there was no significant difference between two groups. Mean serum vitamin D levels in the asthma patient group were detected as $14.20 \pm 6.74 \mathrm{ng} / \mathrm{ml}$ and $14.70 \pm 5.63 \mathrm{ng} / \mathrm{ml}$ for females and males, respectively $(p=0.062)$. In the control group, however, no significant difference between average serum vitamin $\mathrm{D}$ levels between females $(16.10 \pm 6.55 \mathrm{ng} / \mathrm{ml})$ and males $(19.96 \pm 6.28 \mathrm{ng} / \mathrm{ml})(\mathrm{p}=0.026)$. When groups were classified in terms of vitamin D deficiency based on mean ages, no significant difference was found $(p=0.152)$. No correlation was present between the groups in terms of vitamin D levels and Total IgE level and eosinophil count ( $p>0.05)$. No significant association between vitamin $\mathrm{D}$ deficiency and FEV1 and FEV1/FVC was detected in neither patient nor control groups.
A significant difference was found between severity of asthma and vitamin D deficiency $(p=0.003)$. Examining patients being followed for asthma for correlation between vitamin $\mathrm{D}$ deficiency and asthma control a significant difference between vitamin $\mathrm{D}$ deficiency and asthma management was detected $(p=0.004)$. Detailed analysis of asthma patient group for asthma severity and asthma control status according to vitamin $\mathrm{D}$ deficiency also resulted in a significant difference (Table 3).

We also tried to determine the relationship between vitamin $\mathrm{D}$ level and age, gender, BMI, total IgE, eosinophil, FEV1, FEV1/FVC, asthma severity and control (Table 4). There were no correlation between vitamin $\mathrm{D}$ level and age, gender, BMI, total IgE, eosinophil, FEV1, FEV1/FVC. We found significant negative correlation between vitamin $\mathrm{D}$ deficiency and mild persistent asthma, uncontrolled asthma and partly controlled asthma (Table 4).

TABLE 3. According to vitamin D deficiency, detailed evaluation of patient group for asthma severity and control status

\begin{tabular}{|c|c|c|c|c|}
\hline & $\begin{array}{l}\text { Vitamin D deficiency } \\
(<15 \mathrm{ng} / \mathrm{ml})\end{array}$ & $\begin{array}{l}\text { Vitamin D insufficiency } \\
(15-20 \mathrm{ng} / \mathrm{ml})\end{array}$ & $\begin{array}{l}\text { Normal vitamin D level } \\
(>20 \mathrm{ng} / \mathrm{ml})\end{array}$ & $p$ \\
\hline \multicolumn{5}{|l|}{ Asthma severity n (\%) } \\
\hline Intermittent asthma & $16(44.4)$ & $8(22.2)$ & $12(33.3)$ & 0.012 \\
\hline Mild persistent asthma & $22(61.1)$ & $12(33.3)$ & $2(5.6)$ & \\
\hline \multicolumn{5}{|l|}{ Asthma control (\%) } \\
\hline Well-controlled & $9(36)$ & $6(24)$ & $10(40)$ & 0.007 \\
\hline Partly controlled & $23(65.7)$ & $8(22.9)$ & $4(11.4)$ & \\
\hline Uncontrolled & $6(50)$ & $6(50)$ & $0(0)$ & \\
\hline
\end{tabular}

TABLE 4. Correlation between vitamin D levels and patients variables

\begin{tabular}{lcccccc}
\hline & \multicolumn{2}{c}{$\begin{array}{c}\text { Vitamin D deficiency } \\
(<\mathbf{1 5} \mathbf{~ n g} / \mathbf{m l})\end{array}$} & \multicolumn{2}{c}{$\begin{array}{c}\text { Vitamin D insufficiency } \\
(\mathbf{1 5 - 2 0} \mathbf{~ n g} / \mathbf{m l})\end{array}$} & \multicolumn{2}{c}{$\begin{array}{c}\text { Normal Vitamin D Level } \\
(>\mathbf{2 0} \mathbf{~ n g} / \mathbf{m l})\end{array}$} \\
& $\mathbf{p}$ & $\mathbf{r}$ & $\mathbf{p}$ & $\mathbf{r}$ & $\mathbf{p}$ & $\mathbf{r}$ \\
\hline Gender & 0.820 & 0.130 & 0.699 & 0.243 & 0.377 & 0.187 \\
Age & 0.389 & 0.114 & 0.343 & 0.331 & 0.519 & 0.100 \\
BMI & 0.924 & 0.228 & 0.551 & 0.149 & 0.874 & 0.056 \\
Total Ig E & 0.324 & -0.650 & 0.265 & -0.598 & 0.493 & 0.185 \\
Eosinophil & 0.307 & -0.743 & 0.298 & -0.412 & 0.264 & 0.192 \\
FEV1 & 0.471 & 0.122 & 0.172 & 0.136 & 0.507 & 0.167 \\
FEV1/FVC & 0.190 & 0.633 & 0.104 & 0.136 & 0.228 & 0.549 \\
Asthma Severity & & & & & & \\
$\quad$ Intermittent asthma & 0.078 & -0.576 & 0.123 & -0.654 & 0.094 & 0.732 \\
$\quad$ Mild persistent asthma & 0.015 & -0.634 & 0.093 & -0.745 & 0.132 & 0.672 \\
Asthma control & & & & & \\
$\quad$ Well-controlled & 0.436 & -0.134 & 0.157 & -0.402 & 0.284 & 0.094 \\
$\quad$ Partly controlled & 0.076 & -0.094 & 0.108 & -0.603 & 0.704 & -0.132 \\
$\quad$ uncontrolled & 0.011 & -0.671 & 0.031 & -0.517 & 0.107 & 0.343 \\
\hline
\end{tabular}




\section{DISCUSSION}

Asthma prevalence and vitamin D deficiency rates have been increasing worldwide. An increasing body of evidence supports the pleotropic effects of vitamin D on various chronic disorders including those associated with immune regulatory function. ${ }^{14}$ Vitamin D deficiency has been shown to be a risk factor in the development of serious chronic diseases where inflammatory mechanisms play a role in the pathogenesis. ${ }^{15}$ In our study, we planned to investigate the effect of serum vitamin $\mathrm{D}$ levels and deficiency on the development, severity, and control of asthma.

Vitamin D levels are especially affected by seasonal changes. In the study by Freishtat et al. compared to summer months, in AfricanAmerican asthma patients, vitamin D levels were shown to be statistically significantly lower in winter months. ${ }^{16}$ Therefore, our study was conducted in winter months.

Vitamin D levels have been shown to be statistically significantly lower in asthmatic chil dren compared to the healthy children in studies of Mediterranean countries such as Italy, Cyprus, and Turkey, as well as Middle Eastern countries such as Iran and Qatar., ${ }^{7,15,16}$ In our study; the average serum vitamin D levels in the asthma patient group was found to be significantly lower compared to the control group ( $\mathrm{p}<0.004)$. When asthma patient group and control group was compared according to vitamin $\mathrm{D}$ deficiency and normal vitamin $\mathrm{D}$ levels, the number of cases with decreased vitamin D levels in the patient was found to be significantly higher than the control group ( $\mathrm{p}<0.041$ ).

In the epidemiological studies; the increased amount vitamin $\mathrm{D}$ taken by mothers during pregnancy was found to be associated with reduced risk for recurring wheezing attacks at the age of three. ${ }^{17}$ Devereux et al reported decreased vitamin $\mathrm{D}$ intake during pregnancy resulted in significantly lower response to bronchodilator. ${ }^{18}$ In a study conducted in New Zealand, reduced $25(\mathrm{OH}) \mathrm{D}$ levels in cord blood was shown to increase respiratory tract infection and childhood wheezing. ${ }^{19}$ The limiting factor in these studies was failure to determine precisely the amount of vitamin D intake through nutrition and as supplement.

In recent studies, the effect of vitamin $\mathrm{D}$ on pulmonary functions was investigated. ${ }^{20,21} \mathrm{In}$ a study conducted in North America on 1024 children with asthma, a positive correlation was found between vitamin $\mathrm{D}$ deficiency and reduced FEV1. ${ }^{21}$ Searing et al. found a positive correlation between low vitamin D levels and FEV1 and FEV / FVC ratio. ${ }^{22}$ Following standardization according to age, gender, race, BMI and smoking history, the data review of the NHANNES III study conducted in United States of America by Black et al, a strong association was detected between serum vitamin D levels and FEV1 and $\mathrm{FVC}^{21}$ In a cross sectional study conducted in Italy on asthma patients, a meaningful relation between reduced vitamin D levels and reduced FVC levels was found, however a statistically significant association between FEV1 and FEV1/ FVC was not detected.$^{23}$ In our study a statisticiallyrelation between vitamin $\mathrm{D}$ deficiency and FEV1 and FEV1/FVC was not found.

The effect of vitamin D on asthma control and severity; appears as increased response to corticosteroids and reduced asthma exacerbation risk. Inhaled corticosteroids are medicines used with good response in asthma treatment that reduce symptoms and serious asthma exacerbation, improves respiratory functions and increase quality of life in asthma patients. ${ }^{11}$

In the general population, the association of vitamin D with asthma thus far, there is an inverse relationship between sufficient levels of vitamin D and asthma medication use, and asthma severity indicators such as exacerbation and hospitalization in children with asthma. ${ }^{16,24}$

In the study conducted on 100 children with asthma Searing et al. found an association between low serum vitamin $D$ levels and high dose corticosteroid use and low respiratory function tests. ${ }^{22}$ In the same study, when dexamethasone and vitamin $\mathrm{D}$ was administered concurrently, MPK-1 and IL10 mRNA levels increased significantly more than the cases administered only dexamethasone.

In our study, there were 36 patients with intermittent and 36 mild persistent asthma. Since the number of patients with moderate or severe persistent asthma visiting Pediatric Allergy Department was low, these patients were not included in the study. In $24(66.7 \%)$ of the 36 patients with intermittent asthma and 34 (94.4\%) of the 36 mild persistent asthma patients, vitamin $\mathrm{D}$ deficiency $(<20 \mathrm{ng} / \mathrm{ml})$ was detected $(\mathrm{p}=0.003)$. Comparison of patients based on vitamin $\mathrm{D}$ level and number of attacks showed patients with low vitamin $D$ levels had more attacks within the previous year $(\mathrm{p}=0.048, \mathrm{r}=-0.234)$. 
In our study, a significant difference between skin test and $25(\mathrm{OH}) \mathrm{D}$ level was not found $(p=0.360)$. These results are similar with the finding of the Tamašauskienè et al study. ${ }^{25}$

In our study, correlation between Vitamin D deficiency and serum calcium, phosphorus and alkaline phosphatase was investigated but no statistically significant relationship was found.

There are some limitations in this study. First of all, the sample size is relatively small, which decreases the power of the study. Statistically insignificant associations might become significant in future studies with larger sample sizes. The study was conducted in a single center and out of the factors affecting Vitamin D levels (nutrition, sun effects and dressing style) could not be precisely evaluated. Vitamin $D$ levels of the mother during pregnancy was unknown, eating frequency surveys were not utilized, VDR genetic variants were not investigated in blood samples, patients were not followed for seasonal evaluation. After supplemental vitamin use, Vitamin D deficient patients were not reevaluated. To the best of our knowledge, this study is the first trial to control design study both vitamin $\mathrm{D}$ level and severity and asthma control in school age patients in Turkey.

The small sample sizes of trials included in pooled analyses resulted in poor precision of effect estimates and prevented us from conducting sensitivity. Further, because vitamin $\mathrm{D}$ is thought to enhance the response to steroids and to play a role in the regulation of immune function, it would have been relevant to perform sub-group analyses on trials in which vitamin D was given as an adjunct to improve the clinical efficacy of other forms of asthma treatment. However, we could not perform such analyses and the effect estimates obtained from combining trials with vitamin $\mathrm{D}$ given alone or as an adjunct (to steroids and/or immunotherapy) may mask this biological interaction effect. In the absence of a sufficient number of trials that would allow direct comparisons of similar interventions on standardized and clinically important outcomes, our ability to detect a causal effect for a defined intervention was limited.

In conclusion, the frequency of vitamin $\mathrm{D}$ deficiency and insufficiency was higher in children with asthma, compared to the controls. Therefore, we suggest that lower levels of vitamin $\mathrm{D}$ are associated with poor asthma control and increased asthma severity.

\section{REFERENCES}

1. Horak F, Doberer D, Eber E, et al. Diagnosis and management of asthma - Statement on the 2015 GINA Guidelines. Wien Klin Wochenschr 2016;128(15-16):541-54.

2. Önes U, Akçay A, Tamay Z, et al. Rising trend of asthma prevalence among Turkish schoolchildren (ISAAC phases I and III). Allergy 2006;61(12):1448-53.

3. Worldwide variations in the prevalence of asthma symptoms: the International Study of Asthma and Allergies in Childhood (ISAAC). Eur Respir J 1998;12(2):315-35.

4. Holick MF. Vitamin D deficiency in 2010: health benefits of vitamin D and sunlight: a D-bate. Nat Rev Endocrinol 2011;7(2):73-5.

5. Hypponen E, Power C. Hypovitaminosis Din British adults at age $45 \mathrm{y}$ : nationwide cohort study of dietary and lifestyle predictors. Am J Clin Nutr 2007;85(3):860-8.

6. Brown SD, Calvert HH, Fitzpatrick AM. Vitamin D and asthma. Dermatoendocrinol 2012;4(2):137-45.

7. Litonjua AA. Childhood asthma may be a consequence of vitamin D deficiency. Curr Opin Allergy Clin Immunol 2009;9(3):202-7.

8. Asilsoy S. Vitamin D and allergic diseases. Asthma Allergy Immunol 2011;9:1-7.

9. Xystrakis E, Kusumakar S, Boswell S, et al. Reversing the defective induction of IL-10-secreting regulatory $\mathrm{T}$ cells in glucocorticoid-resistant asthma patients. J Clin Invest 2006;116(1):146-55.

10. Della Giustina A, Landi M, Bellini F, et al. Vitamin D, allergies and asthma: focus on pediatric patients. World Allergy Organ J 2014;7(1):27.

11. National Heart, Lung and Blood Institute. National Asthma Education and Prevention Program, Expert Panel Report3: Guidelines for the Diagnosis and Management of Asthma: Full Report 2007. Bethesda: National Institutes of Health; 2007.

12. Neyzi O, Günöz H, Furman A, et al. Türk çocuklarında vücut ağırlığı, boy uzunluğu, baş çevresi ve vücut kitle indeksi referans değerleri. Çocuk Sağhı̆̆ı ve Hastalıkları Dergisi 2008;51(1):1-14.

13. Giner J. The American Thoracic Society/European Respiratory Society acceptability criteria for spirometry: asking too much or not enough?--Reply. Respir Care 2015;60(5):e114.

14. Turkeli A, AyazO, Uncu A, et al. Effects of vitamin D levels on asthma control and severity in pre-school children. Eur Rev Med Pharmacol Sci 2016;20(1):26-36.

15. Theodoratou E, Tzoulaki I, Zgaga L, et al. Vitamin D and multiple health outcomes: umbrella review of systematic reviews and meta-analyses of observational studies and randomised trials. BMJ 2014;348:g2035.

16. Doğru M, Kırmızıbekmez H, Yesiltepe Mutlu RG, et al. Clinical effects of vitamin $\mathrm{D}$ in children with asthma. Int Arch Allergy Immunol 2014;164(4):319-25.

17. Litonjua AA, Carey VJ, Laranjo N, et al. Effect of prenatal supplementation with vitamin $\mathrm{D}$ on asthma or recurrent wheezing in offspring by age 3 years: the VDAART randomized clinical trial. JAMA 2016;315(4):362-70.

18. Devereux G, Litonjua AA, Turner SW, et al. Maternal vitamin $\mathrm{D}$ intake during pregnancy and early childhood wheezing. Am J Clin Nutr 2007;85(3):853.9.

19. Camargo CAJr, Ingham T, Wickens K, et al. Vitamin D status of newborns in New Zealand. Br J Nutr 2010;104(7):1051-7.

20. Gazibara T, den Dekker HT, de Jongste JC, etal. Associations of maternal and fetal 25-hydroxyvitamin D levels with childhood lung function and asthma: the Generation $\mathrm{R}$ Study. Clin Exp Allergy 2016;46(2):337-46.

21. Brehm JM, Schuemann B, Fuhlbrigge AL, et al. Serum 
Vitamin D levels and severe asthma exacerbations in the Childhood Asthma and Management Program study. J Allergy Clin Immunol 2010;126(1):52-8.

22. Searing DA, Zhang Y, Murphy JR, et al. Decreased serum Vitamin D levels in children with asthma are associated with increased corticosteroid use. J Allergy Clin Immunol 2010;125(5):995-1000.

23. Burns JS, Dockery DW, Neas LM, et al. Low dietary nutrient intakes and respiratory health in adolescents. Chest 2007;132(1):238-45.

24. Brehm JM, Acosta-Pérez E, Klei L, et al. Vitamin D insufficiency and severe asthma exacerbations in Puerto Rican children. Am J Respir Crit Care Med 2012;186(2): 140-6.

25. Tamašauskienè L, Gasiūnienė E, Lavinskienè S, et al. Evaluation of vitamin D levels in allergic and non-allergic asthma. Medicina (Kaunas) 2015;51(6):321-7. 